\title{
CSF cytology versus immunocytochemistry in meningeal carcinomatosis
}

\author{
W BOOGERD, TH M VROOM, P VAN HEERDE, G BRUTEL DE LA RIVIÈRE, \\ J L PETERSE, J J VAN DER SANDE \\ From the Departments of Neurology and Pathology of the Netherlands Cancer Institute (Antoni van \\ Leeuwenhoekhuis) and the Municipal Hospital Slotervaart, Amsterdam, The Netherlands
}

SUMMARY CSF immunocytochemistry with monoclonal antibodies was compared with conventional cytology to determine its sensitivity in detecting malignant cells in patients with meningeal carcinomatosis. One hundred and eighteen samples were investigated. Cytology was tumour positive in 83 samples and immunocytochemistry in 85 . Dissimilar results between the two diagnostic methods were noted in 12 specimens, invariably occurring in samples with a low cell count and obtained from treated patients. Combined use of the two methods led to a $9 \%$ increase of sensitivity in detecting malignant cells compared with cytology alone. It is concluded that immunocytochemistry is of minor help in the problem of false-negative cytology in meningeal carcinomatosis.

Infiltration of the leptomeninges by metastases from solid tumours is a relatively rare condition. It has, however, been recognised with increasing frequency in recent years. ${ }^{12}$ Left untreated, leptomeningeal metastases will produce progressive neurological deficit and usually lead to death in about 6 weeks. ${ }^{34}$

Treatment with intrathecally administered chemotherapy, particularly methotrexate (MTX) either alone or combined with radiation therapy (RT) has been shown to improve survival with remission of neurological symptoms and signs in the majority of the treated patients. ${ }^{56}$ As the clinical course depends on early treatment, a rapid and accurate method of early diagnosis is needed.

The diagnosis is generally made by demonstrating malignant cells in the cerebrospinal fluid (CSF). However, failure to detect tumour cells in CSF is not rare, even after repeated examinations. ${ }^{367}$ The use of monoclonal antibodies on CSF cells should increase the accuracy of diagnosing meningeal carcino-

Address for reprint requests: Dr Boogerd, Department of Neurology, Slotervaartziekenhuis, Louwesweg 6, 1066 EC Amsterdam, The Netherlands.

Received 16 June 1987. Accepted 20 July 1987 matosis. ${ }^{8}$ Apart from the possibility of identifying the type of neoplasm from which the malignant cells originate, immunocytochemical examination has also been reported to be more sensitive than cytology in detecting malignant cells. ${ }^{910}$

The present study has been performed to assess the sensitivity of immunocytochemistry compared with cytology in detecting malignant cells in CSF of patients with meningeal carcinomatosis.

\section{Materials and methods}

From 20 consecutive patients with clinical signs or a history of meningeal carcinomatosis $118 \mathrm{CSF}$ specimens were investigated (table). In all patients the diagnosis of malignant disease had been made previously. Fifteen specimens were obtained by lumbar puncture and 103 by a ventricular tap via an Ommaya reservoir.

All patients, except patients nos 2 and 19, were treated with intrathecal injection of chemotherapeutic agents. This treatment was combined with local irradiation in eight patients.

For cytological and immunocytochemical examination equal aliquots of $2 \mathrm{ml}$. CSF from each puncture were sampled and immediately transported to the laboratories for further processing. For both examinations slides were prepared by the cytocentrifuge technique (Shandon Elliot cytospin).

For immunocytochemical examination, in principle at 
Table Results of CSF cytology compared with immunocytochemistry in patients with meningeal carcinomatosis

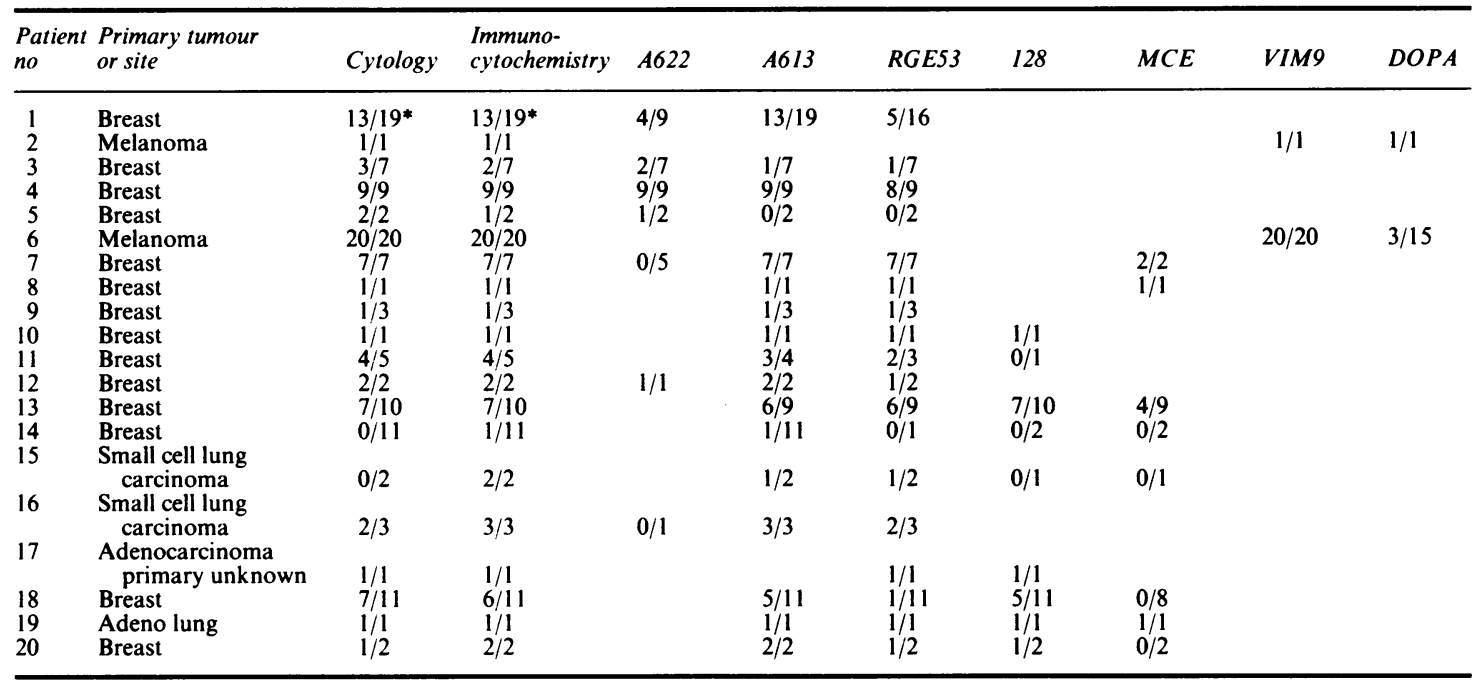

*No. positive/No. done.

least three slides were prepared from each sample for staining with different monoclonal antibodies. However, from samples with a low cell count (less than 1 cell per $\mathrm{mm}^{3}$ ) only two slides were prepared.

For cytological examination the slides were airdried, fixed in methanol and routinely stained with Giemsa and investigated in the Department of Pathology of the Antoni van Leeuwenhoek Ziekenhuis (PvH, JLP). Immunocytochemical investigation was carried out in the Department of Pathology of the Slotervaartziekenhuis (GB, $\mathrm{ThV}$ ). The slides were fixed in acetone for 15 minutes at $-20^{\circ} \mathrm{C}$, then washed for 15 minutes in phosphate buffered saline (PBS) pH 7.4 at $4^{\circ} \mathrm{C}$, and for 15 minutes in PBS at $20^{\circ} \mathrm{C}$. Thereafter the slides were incubated for 30 minutes at $20^{\circ} \mathrm{C}$ with the primary monoclonal mouse antibody and washed for 30 minutes in three changes of PBS. Finally they were incubated with rabbit antimouse Ig labelled with alkaline phosphatase, 1:20 diluted with 10\% normal human serum. The activity of this enzyme was visualised according to Li et al. ${ }^{11}$ Dependent on the primary tumour, the following monoclonal antibodies were used: in breast carcinoma, anti prekeratin (A 622: Dako, Copenhagen, Denmark), anti epithelial membrane antigen (EMA) (A 613: Dako, Copenhagen, Denmark), anti adenokeratin (RGE 53: Eurodiagnostics, Apeldoorn, the Netherlands), anti cytokeratin (128, Immunotech) and anti CEA (MCE, Eurodiagnostics, Apeldoorn, the Netherlands). In malignant melanoma anti vimentin (VIM 9: Monosan-Sanbio, Uden, the Netherlands), and a DOPA reaction. ${ }^{12}$ In small cell lung cancer $A$ 622, A 613, RGE 128 and MCE. In adenocarcinoma of the lung and of unknown primary site A 613, RGE 53, 128 and MCE. A choice had to be made out of these antibodies when as a result of a paucity of cells only two slides had been prepared. The investigators concerned with CSF immunocytochemistry were unaware of the results of the CSF cytology examinations and vice versa. The results of cytology and immunocytochemistry were compared afterwards.

\section{Results}

Cytology revealed malignant cells in 83 CSF specimens and was negative in 35 specimens (table). The results of immunocytochemistry were almost equivalent: positive in 85 and negative in 33 specimens. In 12 specimens, all obtained from treated patients (nos $1,3,5,14,15,16,18$ and 20 ) the results of cytology and immunocytochemistry were dissimilar. In five specimens cytology appeared to be positive while immunocytochemistry was negative; in seven specimens immunocytochemistry was positive and cytology negative. Applying both diagnostic methods in combination would have resulted in 90 positive samples. This means an increase in the detection of malignant cells of $9 \%$ compared with cytology alone. No clear difference could be found in the number of positive cells between the two methods, including several specimens containing less than one cell per $\mathrm{mm}^{3}$ as counted with a Fuchs-Rosenthal chamber. In all controversial specimens the cell count was within normal limits with a positive result based on a single or a few positive cells. The specimens with negative cytology and immunocytology were derived from patients treated with intrathecal chemotherapy.

\section{Discussion}

In leukaemia meningeal involvement is a common 
complication with important therapeutic consequences. Difficulties in establishing the diagnosis in meningeal leukaemia by CSF cytology is well known ${ }^{13}$ and the value of immunocytochemistry in these instances has been well established. ${ }^{14}$ Though treatment response in meningeal carcinomatosis is less favourable than in meningeal leukaemia, some recent studies have demonstrated complete remission or substantial improvement of clinical symptoms after intrathecal chemotherapy. ${ }^{56}$ Improvement is less likely if treatment is initiated later in the course of the disease when neurological deficit is overt. Therefore an early and accurate diagnosis is of clinical importance. The presence of malignant cells in the CSF of patients with solid tumours provides conclusive evidence for meningeal carcinomatosis. ${ }^{3}$ However, absence of malignant cells does not exclude the diagnosis. In a study with necropsy verified cases a false-negative CSF cytology was noted in $41 \%{ }^{3}$ This high percentage is concordant with other surveys. ${ }^{7} \mathrm{As}$ can be expected, the false-negative rate seems to be lower in studies concerning patients with meningeal carcinomatosis without extensive post-mortem investigation. ${ }^{515}$ Except for a positive cytology, the bead-like defects occasionally found at myelography or contrast enhancement in the cisterns and cerebral sulci on CT scans are also considered as conclusive evidence of the diagnosis meningeal carcinomatosis. An increase of biochemical tumour markers in the CSF, as well as other CSF abnormalities like high pressure, hypoglycorrachia and an increased protein concentration, are more frequently encountered than a positive cytology ${ }^{6}$ However, these findings are less specific than CSF cytology and insufficient for establishing the diagnosis unless typical clinical signs of meningeal carcinomatosis are present.

Immunocytochemical staining of CSF tumour cells can be of great value in identifying an unknown primary tumour. ${ }^{9}$ Apart from this increased specificity immunocytochemistry has been reported to be more sensitive than routine cytology in detecting malignant cells: the detection of malignant cells in six patients with meningeal carcinomatosis increased from $25 \%$ to $100 \%$ by applying immunocytochemistry. ${ }^{10}$ In our experience, however, malignant cells can, in cases of meningeal carcinomatosis, usually clearly be distinguished from non-malignant cells by conventional cytology. In the present study the results of cytology and immunocytochemistry were almost similar in positive as well as in negative findings, including many specimens with a very low cell count. The sensitivity in the detection of malignant cells increased by less than $2 \%$ by applying immunocytochemistry, while it increased by $9 \%$ when both diagnostic methods were used in combination. We examined particularly samples from patients with treated meningeal carcinomatosis, to see whether a consistent discrepancy in sensitivity between the two methods could be determined in samples with a normal cell count. The discordant results were invariably found in samples with a low cell count, obtained from patients showing a clinical response to treatment. The dissimilarity was always based on a single or a few positive cells, indicating that the difference is presumably caused by a sampling error. As the number of positive cells was about the same with both methods, the use of larger amounts of CSF would probably not have altered this conclusion. This study demonstrates that CSF immunocytochemistry in patients with meningeal carcinomatosis from a known primary tumour is not superior to routine CSF cytology in the detection of malignant cells. Applying both methods in combination is only of some value in samples with a very low cell count; it will not substantially influence the choice of therapy. By reason of the costs and the length of time of these methods, CSF cytology should be preferred to immunocytochemistry as a diagnostic test for meningeal carcinomatosis in patients with a known primary tumour.

We thank Miss $\mathbf{M}$ van den Elzen for typing the manuscript.

\section{References}

1 Nugent JL, Bunn PA, Matthews MJ, et al. CNS metastases in small cell bronchogenic carcinoma-increasing frequency and changing patterns with lengthening survival. Cancer 1979;44:1885-93.

2 Yap HY, Yap BS, Tashima CK, Distefano A, Blumenschein GR. Meningeal carcinomatosis in breast cancer. Cancer 1978;42:283-6.

3 Glass JP, Melamed M, Chernik NL, Posner JB. Malignant cells in cerebro-spinal fluid (CSF): The meaning of a positive CSF cytology. Neurology 1979;29:1369-75.

4 Little JR, Dale AJD, Okazaki H. Meningeal carcinomatosis. Clinical manifestations. Arch Neurol 1974;30:138-43.

5 Ongerboer de Visser BW, Somers R, Nooyen WH, van Heerde P, Hart AAM, McVie JG. Intraventricular methotrexate therapy of leptomeningeal metastases from solid tumors. Cancer 1982;49:759-72.

6 Wasserstrom WR, Glass JP, Posner JB. Diagnosis and treatment of leptomeningeal metastases from solid tumors. Cancer 1982;49:759-72.

7 Olson ME, Chernik NL, Posner JB. Infiltration of the leptomeninges by systemic cancer. A clinical and pathologic study. Arch Neurol 1974;30:122-37.

8 Hancock WW, Medley G. Monoclonal antibodies to identify tumor cells in CSF. Lancet 1983;ii:739-40.

9 Coakham HB, Harper EL, Garson JA, Brownell B, Lane EB. Carcinomatous meningitis diagnosed with monoclonal antibodies. Br Med J 1984;1:1272.

10 Coakham HB, Brownell B, Harper EL, et al. Use of 
monoclonal antibody panel to identify malignant cells in cerebrospinal fluid. Lancet 1984;i:1095-8.

11 Li CY, Yam LT, Crosby WH. Histochemical characterization of cellular and structural elements of the human spleen. $J$ Histochem 1972;20:1049-58.

12 Burstone MS. Enzyme Histochemistry. New York: Academic Press, 1962:465-6.

13 Borowitz M, Bigner SH, Johnston WW. Diagnostic problems in the cytologic evaluation of cerebrospinal fluid for lymphoma and leukemia. Acta Cytol 1981;23:665-74.

14 Goodson JD, Strauss GM. Diagnosis of lympomatous leptomeningitis by cerebrospinal fluid lymphocyte cell surface markers. Am J Med 1979;66:1057-9.

15 Theodore WH, Gendelman S. Meningeal carcinomatosis. Arch Neur 1981;38:696-9. 